\title{
An Observational Study of the Clinical Profile of Congenital Hypothyroidism in Children.
}

\author{
Shiji Joseph ${ }^{1}$, Lulu Mathews ${ }^{2}$, Vijayakumar $\mathbf{M}^{3}$ \\ ${ }^{1}$ Assistant Professor, Department of Paediatrics, Amala Institute of medical sciences, Thrissur, Kerala, ${ }^{2}$ Retd. Professor \& former HOD, Department of Paediatrics, \\ Govt Medical College Calicut, Kerala, ${ }^{3}$ Prof \& HOD, Department of Paediatrics, Govt Medical College Manjeri, Malappuram, Kerala.
}

\section{Abstract}

Background: Thyroid hormones are important for the general growth and development of the infant and the child, particularly in the differentiation and function of the nervous system. They are essential in the maturational events involved in the transition of the neonate to the adult. Subjects and Methods: The prospective, observational study was conducted in Department of Pediatrics, Institute of Maternal and Child Health, Calicut Medical College for a period of two years. After getting informed consent from the parents, history was taken followed by physical and systemic examination of the baby. Physical and systemic examination was done. Anthropometric measurements were taken and laboratory investigations were done. Results are expressed in terms of frequencies and means. Data is analyzed using SPSS. Results: Congenital hypothyroidism is often diagnosed very late. Mean age at diagnosis was 1.32 year in the present study. Birth weight may not be a clinically useful indicator of congenital hypothyroidism. Absence of classical clinical features in the new born period is the major reason for the delay in diagnosis. With delay in diagnosis of congenital hypothyroidism the predominant clinical features are those of prolonged hypothyroid state like microcephaly, short stature, macroglossia, dry skin and delayed bone age. Conclusion: Any child with facial puffiness, recent onset poor scholastic performance or excessive sleepiness with or without goiter should be suspected to have juvenile hypothyroidism and evaluated.

Keywords: Congenital, Hypothyroidism, children, symptoms.

Corresponding Author: Dr. Shiji Joseph, Assistant Professor, Department of Paediatrics, Amala Institute of medical sciences, Thrissur, Kerala.

Received: December 2018

Accepted: February 2019

\section{Introduction}

Thyroid hormones are important for the general growth and development of the infant and the child, particularly in the differentiation and function of the nervous system. They are essential in the maturational events involved in the transition of the neonate to the adult. ${ }^{[1]}$

Hypothyroidism is the commonest endocrinological problem in childhood and it is a preventable cause of mental retardation. ${ }^{[1]}$ Early detection and careful and skillful follow up has been shown to prevent much of the morbidity associated with the hypothyroid state. ${ }^{[2]}$

Hypothyroidism in children can be due to congenital causes and acquired causes. Congenital hypothyroidism is usually seen and detected in infancy whereas acquired hypothyroidism though typically seen in adolescence can occur as early as in the first year of life. ${ }^{[3]}$

Being a preventable cause of mental retardation, several studies have been carried out in the world for early detection of congenital hypothyroidism. Most of these studies were based on newborn screening program for congenital hypothyroidism. ${ }^{[4]}$

At birth, the clinical signs and symptoms of congenital hypothyroidism are usually absent or so nonspecific or subtle that the majority of infants look completely normal. The development of features of hypothyroidism will depend upon the type of the defect, the age of onset and the duration and severity of the thyroid hormone deficiency. Since irreversible damage to the central nervous system may take place even before the clinical manifestations suggest the diagnosis, the early detection and treatment is critical to the mental development. ${ }^{[5,6]}$

Acquired hypothyroidism is usually seen in school aged children and the first and often unrecognized feature is deceleration of growth. Chronic lymphocytic thyroiditis is the most common cause of this disorder though iatrogenic, autoimmune and other diseases contribute to this state. ${ }^{[7]}$

With the introduction of highly sensitive radioimmunoassay for the detection of thyroid hormones and TSH, newborn screening has come to the forefront as a part of the general system of delivering health care in developed countries. However, in developing countries like India the economic and social problems involved in screening a vast population of neonates, most of whom are from rural areas, are formidable. Therefore, the awareness of the signs and symptoms of congenital hypothyroidism will help the clinician to diagnose the disease as early as possible so that we can prevent one of the most important preventable 
causes of mental retardation. ${ }^{[8]}$

All premature infants have some degree of hypothyroxinemia. ${ }^{[9]}$ This hypothyroxinemia is transient correcting spontaneously over 4-8 weeks. Postnatal growth and development is normal so that they do not require treatment and treatment does not increase growth rates. ${ }^{[10]}$

The clinical profile depends on the underlying etiology, the age of onset and the duration of thyroid deprivation before seeking medical attention. The classical clinical picture of well-established disease is unmistakable but the detection of the disorder in the newborn and young infants, where symptoms and signs are often vague and nonspecific poses problems. Less than $5 \%$ of the newborns detected on screening can be diagnosed clinically and in the best of the clinics, only $10 \%$ may be clinically diagnosed by 2 months and $30 \%$ by three months. ${ }^{[9]}$ There is a tendency for prolonged gestation ( $20 \%$ greater than 42 weeks) among the mothers, the mean birth weight and length are near the 50th percentile, and the head circumference will be near the 70th percentile. In the newborn period, length and weight are normal.

Prolonged physiological jaundice may be the earliest sign. ${ }^{[11]}$ Hyperbilirubinemia may persist for as long as 7 weeks. The cause of hyperbilirubinemia in hypothyroidism include, delay in maturation of bilirubin conjugating enzymes. It is seen in 10\% of newborn with congenital hypothyroidism. ${ }^{[12]}$ Other features include large posterior fontanel, respiratory distress, and hypothermia, and peripheral cyanosis, hypo activity, feeding difficulty, constipation, abdominal distension, vomiting and edema. ${ }^{[13]}$ Respiratory distress may be associated with nasal congestion, hoarse cry and cyanosis and is caused by myxedema of the tongue, epiglottis, pharynx and larynx. Myxedema is the edema in skin, other tissues, and serous cavities secondary to hypothyroidism. It is due to increased extravasations of plasma proteins and leak of a compensatory increase in lymph flow and protein return rate. The skin can be pale, cool, dry and circulating mottling may be present. Heart murmurs are frequently present and if cyanosis is also present congenital heart disease may be suspected. ${ }^{[14]}$

Patients developing hypothyroidism in early childhood differ from cretins in their clinical manifestations. Symptoms may appear gradually over several years. Linear growth and eruption of teeth become retarded. Mental sluggishness may develop but mental retardation does not occur if the hypothyroidism develops after the 2 nd year of life. ${ }^{[15]}$ The present study was conducted to study the clinical profile of hypothyroidism in children up to 12 years of age.

\section{Subjects and Methods}

The prospective, observational study was conducted in Department of Pediatrics, Institute of Maternal and Child Health, Calicut Medical College for a period of two years.
All children in the age group 0-12 years diagnosed to have hypothyroidism, who are outpatients or inpatients of the Department of Pediatrics, Calicut Medical College.

\section{Exclusion criteria}

Children with

- Major congenital anomalies

- Chromosomal anomalies

- Moderate to severe birth asphyxia

\section{Definitions}

Congenital hypothyroidism:

When the thyroid hormone deficiency features are present since birth. ${ }^{[2]}$

Acquired hypothyroidism (Juvenile hypothyroidism):

A previously normal child subsequently develops thyroid hormone deficiency. ${ }^{[2]}$

\section{Goiter:}

The enlargement of thyroid gland. ${ }^{[4]}$

Myxedema: The mucoprotein and fluid accumulation with the resultant edema seen in hypothyroidism. ${ }^{[3]}$

\section{Methodology}

After getting informed consent, history is taken in detail and a thorough physical examination is done as per the proforma with special emphasis on age at diagnosis and starting treatment, antenatal history of thyroid disease or drug intake, history of delayed passage of meconium, prolonged physiological jaundice, constipation, lethargy, poor feeding, umbilical hernia and developmental delay and in older children history of poor school performance, excessive sleep, facial puffiness, cold intolerance and neck swelling.

Presence of any associated illnesses like insulin dependent diabetes mellitus, adrenal insufficiency or vitiligo was assessed. Parents were asked for any history of consanguinity, thyroid diseases in family and use of iodised salt.

Physical examination included a general examination specifically looking for presence of wide fontanels, hypothyroid facies, jaundice, macroglossia, pseudohypertrophy of muscles, thyroid swelling or myxedema.

Anthropometric parameters were taken as per the Performa. Developmental assessment was done in detail. Systemic examination was done especially nervous system examination in detail for any tone abnormalities and delayed relaxation of ankle jerk.

Investigations included hemoglobin, mean cell volume (MCV), thyroid function test by using chemiluminescence immunoassay and serum cholesterol in all patients. Anti TPO antibody and anti thyroglobulin antibody titre was done in selected patients who were suspected to have acquired hypothyroidism. X-ray for bone age assessment and ultra sound scan of the neck for thyroid gland was done in almost all the patients. FNAC was done in three patients

\section{$\underline{\text { Inclusion criteria }}$}


who presented with a large goiter.

Results are expressed in terms of frequencies and means. Data is analyzed using SPSS.

\section{Results}

Out of the 80 children studied, 61 had congenital hypothyroidism and 19 had acquired hypothyroidism. female to male ratio was $1.44: 1$ [Figure 1]. Mean age at diagnosis was 1.32 year [Figure 2].

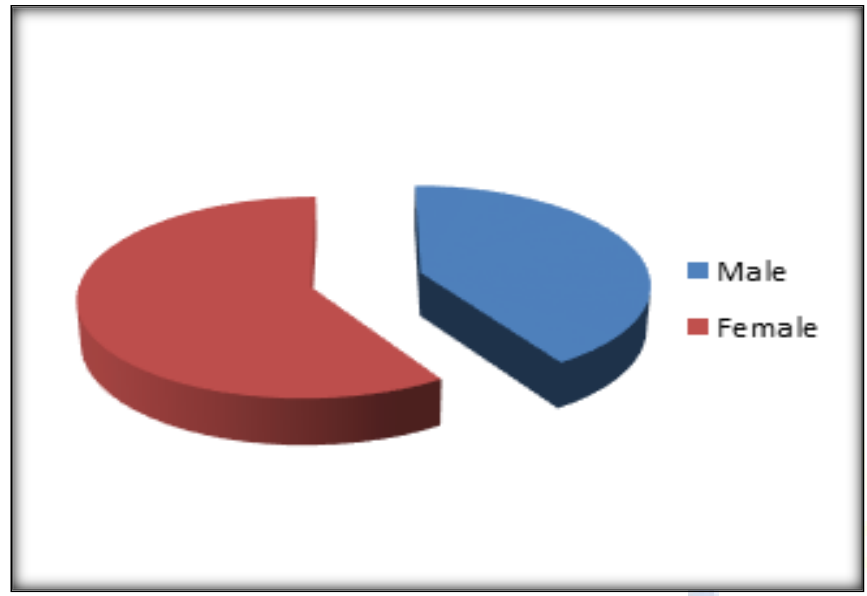

Figure 1: Gender distribution

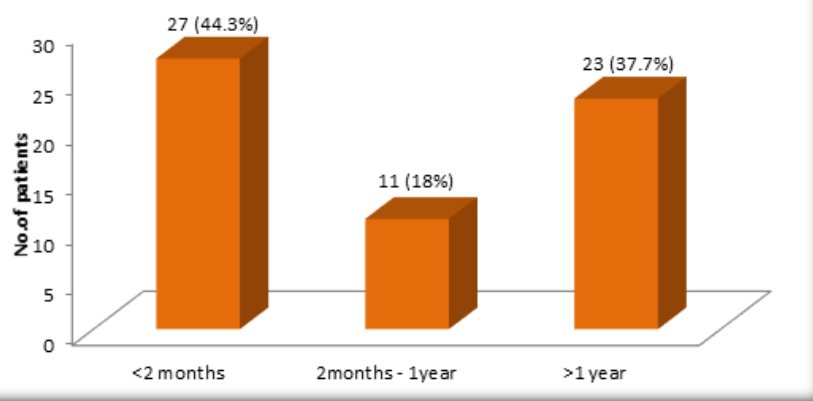

Figure 2: Age at diagnosis

\begin{tabular}{|l|l|l|}
\hline \multicolumn{2}{|c|}{ Table 1: Birth weight $(\mathbf{n}=\mathbf{4 3})$} \\
\hline Wt. $($ Kg) & Number & Percentage \\
\hline$<2.5$ & 13 & 30.2 \\
\hline$>2.5-3.5$ & 26 & 60.5 \\
\hline$>3.5$ & 4 & 9.3 \\
\hline
\end{tabular}

Out of the 61 patients birth weight was available in only 43 patients. 13 had low birth weight, 26 had a birth weight between $2.5-3.5 \mathrm{~kg}$ and only 4 patients had a birth weight more than $3.5 \mathrm{~kg}$ [Table 1].

\begin{tabular}{|l|l|l|}
\hline Table 2: Clinical Features $(\mathbf{n}=\mathbf{6 1})$ \\
\hline Complaints & Number & Percentage \\
\hline Developmental delay & $29 / 34^{*}$ & 85.2 \\
\hline Constipation & 51 & 83.6 \\
\hline Lethargy & 42 & 68.9 \\
\hline Poor feeding & 38 & 62.3 \\
\hline Abdominal distension & 36 & 59 \\
\hline
\end{tabular}

\begin{tabular}{|l|l|l|}
\hline Prolonged jaundice & 20 & 32.8 \\
\hline Delayed passage of meconium & 19 & 31.1 \\
\hline Short stature & 13 & 21.3 \\
\hline Family history & 12 & 19.7 \\
\hline Consanguinity & 7 & 11.5 \\
\hline $\begin{array}{l}\text { Antenatal intake of antithyroid } \\
\text { drugs }\end{array}$ & 2 & 3.3 \\
\hline Thyroid enlargement & 2 & 3.3 \\
\hline
\end{tabular}

Out of 61 patients, 27 were diagnosed before 2 months of age whose development was difficult to assess at that point of time. Hence out of the remaining 34 patients, 29 had developmental delay [Table 2].

Table 3: Anthropometry $(n=61)$

\begin{tabular}{|l|l|l|}
\hline Findings & Number & Percentage \\
\hline Weight & & \\
Over weight & 0 & 0 \\
Normal & 60 & 98.4 \\
Under weight & 1 & 1.6 \\
\hline Length / Height & & \\
Normal & 43 & 70.4 \\
Short stature & 18 & 29.6 \\
\hline Head circumference & & \\
Macrocephaly & 0 & 0 \\
Normal & 55 & 90.2 \\
Microcephaly & 6 & 9.8 \\
\hline
\end{tabular}

Table 4: Physical findings $(n=61)$

\begin{tabular}{|l|l|l|}
\hline Findings & Number & Percentage \\
\hline Hypothyroid facies* & 53 & 86.9 \\
\hline Wide fontanels & 49 & 80.3 \\
\hline Dry skin & 31 & 52.5 \\
\hline Macroglossia & 27 & 44.3 \\
\hline Umbilical hernia & 21 & 34.4 \\
\hline Myxedema & 3 & 4.9 \\
\hline Goiter & 2 & 3.3 \\
\hline *Lid edema, hypertelorism, broad and flat nasal bridge, macroglossia etc.
\end{tabular}

\section{Table 5: Investigations}

Table 5: Investigations
\begin{tabular}{|l|l|l|}
\hline Investigations & Number & Percentage \\
\hline $\begin{array}{l}\text { Abnormal thyroid function } \\
\text { test } \\
\text { Low T4 }\end{array}$ & 50 & 82 \\
$\uparrow T S H$ & 61 & 100 \\
\hline Delayed bone age (n=56) & 42 & 75 \\
\hline $\begin{array}{l}\text { USG thyroid (n=48) } \\
\text { Normal }\end{array}$ & 17 & 35.4 \\
Small & 27 & 56.3 \\
Absent & 4 & 8.3 \\
\hline Low Hb & 12 & 19.7 \\
\hline Elevated serum cholesterol & 7 & 11.5 \\
\hline
\end{tabular}

\section{Discussion}

Out of the 80 patients in the study, 61 patients had congenital hypothyroidism, and 19 patients had acquired hypothyroidism.

Out of the 61 patients, $59 \%$ were females and $41 \%$ were males, with a female to male ratio of $1.44: 1$. This is in concordance with the other major studies which show a $2: 1$ incidence in females compared with males. ${ }^{[16]}$

The mean age at diagnosis was 1.32 year with $44 \%$ being diagnosed before 2 months, $18 \%$ between 2 months to 1 year and $37.7 \%$ after 1 year of age. A study by Desai MP et 
al, ${ }^{[17]}$ showed that nearly $25 \%$ of congenital hypothyroidism is diagnosed by 3 months of age and greater than $70 \%$ after that (without a neonatal screening program). The early diagnosis in this study may be because of the better awareness among the clinicians regarding the clinical features of congenital hypothyroidism now-a-days.

$60 \%$ of our patients had a normal birth weight, $30 \%$ had low birth weight and only $9.3 \%$ had a birth weight greater than $3.5 \mathrm{~kg}$. Birth weight of greater than $3.5 \mathrm{~kg}$ was $18 \%$ in a study by Desai MP et al. ${ }^{[17]}$ Another study 18 showed that $33 \%$ of their patients had birth weight of greater than $4 \mathrm{~kg} 68$. The mean birth weight of normal Indian children is only $2.8 \mathrm{~kg}$ and majority of our patients had normal birth weight. So this might indicate that birth weight may not be a major clinical indicator for the screening of congenital hypothyroidism in our setting.

Table 6: Comparison between Desai MP and present study.

\begin{tabular}{|l|l|l|}
\hline \multirow{2}{*}{ Clinical Features } & Percentage \\
\cline { 2 - 3 } & Desai MP17 & $\begin{array}{l}\text { Present } \\
\text { study }\end{array}$ \\
\hline Birth weight $>3.5 \mathrm{Kg}$ & 18 & 9.3 \\
\hline Constipation & 87 & 82.6 \\
\hline Lethargy & 55 & 69 \\
\hline Poor feeding & 57 & 62.3 \\
\hline Signs & & \\
\hline Hypothyroid facies & 87 & 87 \\
\hline Macroglossia & 87 & 44.3 \\
\hline Dry skin & 66 & 52.5 \\
\hline Large fontanels & 82 & 80.3 \\
\hline
\end{tabular}

The results of the present study were comparable with the other Indian study by Desai MP et al except for parameters like birth weight greater than $3.5 \mathrm{Kg}$ and macroglossia. It shows that all the above tabulated clinical symptoms and signs (except large birth weight and macroglossia which needs confirmation by larger population based studies) can be used as markers of congenital hypothyroidism in our population, as emphasized by various scoring systems (Quebec, Apgar and hypothyroid index) and as shown by other different studies. ${ }^{[6,11,14]}$

The incidence of large birth weight was not that high in the present study as compared to the study by Desai MP17. This may be due to true fact that most of the patients in our study belonged to a lower socioeconomic strata as opposed to a more affluent group in the other study. The incidence of macroglossia was also found to be less in the present study. Our data was obtained from the mother and the old records, which might not have been accurate, thus contributing to the above result.

\section{Other clinical features:}

Umbilical hernia was present in $34 \%$ of our patients, the North west regional screening program showed an incidence of $28 \% .3$ But the another study 8 showed that $58 \%$ of their patients had umbilical hernia. Umbilical hernia was given higher scores in various scoring systems like Quebec (score 1), Apgar (Score 2), hypothyroid index (score 3). The present study showed a lower incidence.

Short stature was a complaint in $21 \%$ of our patients and was observed in $30 \%$ of the study group. These were the children who were diagnosed after 1 year of age. This shows the effect of prolonged hypothyroid state on bone growth and physical development.

Abdominal distension was observed in $9 \%$ in the present study, $20 \%$ in the North west regional screening program and $40 \%$ in the study. ${ }^{[10]}$ It was not included in the study by Desai MP et al, ${ }^{[17]}$ and also in various scoring systems. This is in par with the literatures which denote abdominal distension as a nonspecific finding.

Delayed passage of meconium, though mentioned in the literature as an important finding in congenital hypothyroidism was observed in only $3 \%$ of patients in the present study. ${ }^{[14]}$ This is in accordance with the various scoring systems mentioned. None of them included delayed passage of meconium as a criterion in their scoring system. $90 \%$ of the patients in the present study had normal head circumference and 10\% had microcephaly (all of whom were children with late diagnosis). None of them had macrocephaly. This is comparable to the currently available literature. ${ }^{[7,14]}$

Even though two of the patients had history of thyroid enlargement ultrasound scan did not show any definite increase in the size of the gland in any.

\section{Investigations}

Thyroid function test was abnormal in all the patients. All of them had an elevated TSH. Low T4 was observed in $82 \%$. T4 was normal in $18 \%$. In $11.5 \%$ of the patients elevated Serum cholesterol was found. Anemia was found in only $20 \%$. This observation was not seen in other studies in India. Literature shows that upto $65 \%$ of children with hypothyroidism may be anemic. ${ }^{[1,8]}$

Delayed bone age was observed in $75 \%$ of our patients. Literature, ${ }^{[10,13]}$ review shows that bone age delay is seen in around $60 \%$ of patients at birth. This difference may be because of the fact that many of our patients were diagnosed late, emphasizing the importance of thyroid hormones for normal bone growth and physical development.

\section{Conclusion}

- Congenital hypothyroidism is often diagnosed very late. Mean age at diagnosis was 1.32 year in the present study.

- Birth weight may not be a clinically useful indicator of congenital hypothyroidism.

- Absence of classical clinical features in the new born period is the major reason for the delay in diagnosis.

- With delay in diagnosis of congenital hypothyroidism the predominant clinical features are those of prolonged hypothyroid state like microcephaly, short stature, macroglossia, dry skin and delayed bone age.

- Any child with facial puffiness, recent onset poor scholastic performance or excessive sleepiness with or without goiter should be suspected to have juvenile hypothyroidism and evaluated. 


\section{References}

1. Hung W. Thyroid Gland. In: Hung W. Clinical Pediatric endocrinology. Mosby Yearbook, 1992; 129-178.

2. LaFranchi SH. Hypothyroidism. Pediatr Clin North Am. 1979; 26: $1: 33-51$.

3. LaFranchi S. Disorders of the thyroid gland. IN: Behrman RE, Kleigman RM, Jenson HB, Eds, Nelson Text book of Pediatrics, Harcourt Asia, WB Saunders, New Delhi, 18th edn. 2008; 2316-2332.

4. Dussault JH et al. Preliminary report on a mass screening program for neonatal hypothyroidism. J Pediatr. 1975; 86: 670- 674.

5. Kay C, Abraham S, Malain P. The weight of normal thyroid gland in children. Arch Pathol 1996; 82: 349.

6. Fisher DA, Klein AH. Thyroid development and disorders of thyroid function. N Engl J Med. 1981; 304: 702-708.

7. Burrow GH, Fisher DA, Larsen PR. Maternal and fetal thyroid function. N Engl J Med 1994; 331:1072.

8. Ingbar SH. The thyroid gland. In: Wislon JD, Foster DW eds. Textbook of endocrinology. Philadelphia; WB Saunders, 1985; 682815.

9. Wolff J. Congenital goiter with defective iodine transport. Endocr Rev 1983; 4: 240-54.
10. Stanburry JB, Dumont JE. Familial goiter and related disorders. IN: Stanbury JB et al eds. The metabolic basis of inherited diseases. New York: Mc Graw Hill, 5th Ed, 1983; 231-69.

11. Van Herle AJ, Vassart G, Dumont JE. Control of thyroglobulin synthesis and secretion. N Engl J Med 1979; 301: 239-307.

12. De Nayer P, Cornette C, Vander Shueren $M$ et al. Serum thyroglobulin levels in preterm neonates. Clin Endocrinol 1984; 21: 149-153.

13. Fisher DA. Thyroid hormone and thyroglobulin synthesis sand secretion; In: Delange F, Fisher DA, Malvaux P, eds. Pediatric thyroidology Basel: Karger, 1985; 44-56.

14. Morley JE. Neuroendocrine control of thyotropin secretion. Endocr Rev 1981; 2: 236.

15. Chopra IJ et al. Pathways of metabolism of thyroid hormones. Rec Prog Horm Res 1978; 34: 521-67.

16. Engler D, Burger AG. The deiodination of iodothyronines and of their derivatives in men. Endocr Rev 1984; 5: 131-84,

17. Desai MP. The thyroid gland. In: Desai MP, Vijalakshmi B, Menon PSN. Pediatric Endocrine Disorders, Orient Longman, Hyderabad, 2nd ed, 2007; 285-334.

18. Rees Smith B, McLachlan SM, Furmaniak J. Antuoantibodies to the thyrotropin receptor. Endocr Rev 1988; 9: 106-121.

Copyright: (C) the author(s), 2019. It is an open-access article distributed under the terms of the Creative Commons Attribution License (CC BY 4.0), which permits authors to retain ownership of the copyright for their content, and allow anyone to download, reuse, reprint, modify, distribute and/or copy the content as long as the original authors and source are cited.

How to cite this article: Joseph S, Mathews L, Vijayakumar M. An Observational Study of the Clinical Profile of Congenital Hypothyroidism in Children. Asian J. Med. Res. 2019;8(1):PE01-PE05.

DOI: dx.doi.org/10.21276/ajmr.2019.8.1.PE1

Source of Support: Nil, Conflict of Interest: None declared. 